\title{
RECOVERY OF PLUTONIUM FROM SOLVENT WASH SOLUTIONS (U)
}

\author{
by E. A. Kyser
}

Westinghouse Savannah River Company

Savannah River Site

Aiken, South Carolina 29808

This paper was prepared in connection with work done under Contract No. DE-AC09-89SR18035 with the U. S. Department of Energy. By acceptance of this paper, the publisher and/or recipient acknowledges the U.S. Government's right to retain a nonexclusive, royalty-fres license in and to any copyright covering this paper, along with the right to reproduce and to authorize others to reproduce all or part of the copyrighted paper.

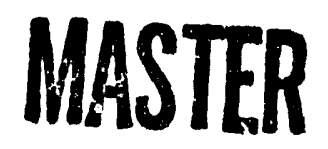




\section{DISCLAIMER}

This report was prepared as an account of work sponsored by an agency of the United States Government. Neither the United States Government nor any agency thereof, nor any of their employees, makes any warranty, express or implied, or assumes any legal liability or responsibility for the accuracy, completeness, or usefulness of any information, apparatus, product, or process disclosed, or represents that its use would not infringe privately owned rights. Reference herein to any specific commercial product, process, or service by trade name, trademark, manufacturer, or otherwise does not necessarily constitute or imply its endorsement, recommendation, or favoring by the United States Government or any agency thereof. The views and opinions of authors expressed herein do not necessarily state or reflect those of the United States Government or any agency thereof.

This report has been reproduced directly from the best available copy.

Available to DOE and DOE contractors from the Office of Scientific and Technical Information, P.O. Box 62, Oak Ridge, TN 37831; prices available from (615) 576-8401, FTS 626-8401.

Available to the public from the National Technical Information Service, U.S. Department of Commerce, 5285 Port Royal Rd., Springfield, VA 22161. 


\section{WESTINGHOUSE SAVANNAH RIVER COMPANY SAVANNAH RIVER LABORATORY}

WSRC-RP-92-0461

Page 1 of 5

March 31, 1992

$\mathrm{CC}:$

C.R. Wolfe, 773-A

A.P. Gouge, 221-F

L.R. Mattingly, 707-F

F.R. Graham, 773-A

D.F. Chostner, 221-F

J.S. Bellamy, 707-F

M.C. Thompson, 773-A

R.A.L Eubanks, 221-F

W.E. Harris, $221-\mathrm{H}$

J.H. Gray, 773-A

R.H. Spires, 221-F

T.A. Reilly, 707-F

D.J. Reif, 773-A

D.M. Delano, 221-14F

J.B. Schaade, 703-F

S.D. Fink, 773-A

S.H. Marek, 221-14F

T.C. Robinson, 221-F

K.D. Bratt, 707-1F

SRL Records (4)

J.S. Evans, 707-F

V.M. Martinez, 221-14F

To:

A.L. Blancett, 773-A

From: $\quad$ E.A. Kyser, 773-A

ADC Samach D. Frib

Recovery of Plutonium from Solvent Wash Solutions (U)

\section{Introduction}

Sodium carbonate solutions used to wash second plutonium cycle solvent during December, 1990 operations contain recoverable plutonium. Earlier, SRL developed a recovery process based on acidification with extended boiling to yield a solid-free acid solution usable as feed for solvent extraction recovery of the plutonium'. Efforts were continued in SRL to establish if alternative flowsheets could be defined offering an advantage over the acid hydrolysis process.

Summary

A number of potential alternatives to the acid hydrolysis recovery of Pu were investigated and are discussed in this report. Most of those alternatives either required extensive development work or were impractical for implementation in $\mathrm{F}$ canyon. The most promising alternative for use in the short term appears to be an anion exchange process that would eliminate the long boiling times and the multiple-pass concentration steps needed with the solvent extraction process because it separates the Pu from the dibutyl phosphate (DBP) while at the same time concentrating the Pu. However, restart of the Primary Recovery Column (PRC) to process this solution would require significant administrative effort.

The original boiling recovery by acid hydrolysis followed by solvent extraction is probably the most expedient way to process the Pu-DBP-carbonate solution currently stored in tank 13.5 even with its long processing times and dilute product concentration. Anion exchange of a heat stabilized acidified solution is a more efficient process, but requires restart of the PRC.

Extended-boiling acid hydrolysis or anion exchange of a heat stabilized acidified solution provide two well developed alternatives for recovery of the Pu from the tank 13.5 carbonate. Further work defining additional recovery processes is not planned at this time.

Keywords: Dibutyl Phosphate, Pu-DBP, Carbonate Solutions, Nonionic Resins, Anion Exchange, Solvent Washing, Second Plutonium Cycle, F Canyon 
WSRC-RP-92-0461

Page 2 of 5

\section{Background}

The carbonate solution used to wash the second plutonium cycle solvent during December 1990 operation is now held in F canyon tank 13.5. SRL developed a recovery flowsheet that made use of acidification in hot nitric acid and an extended boiling cycle to destroy the DBP. That work was documented in Oct 1991 in WSRC-RP-1028'. The investigation of alternative flowsheets to avoid the difficulties associated with extended boiling is described in this report.

The key difficulty in processing this solution is to convert it from a basic medium to an acid medium without the formation of Pu-DBP solids. Although DBP is relatively soluble in acid solution, Pu-DBP has a plant history of forming solids; e.g., in the cation exchange equipment in FB-Line. The approach taken in the initial work was to allow acid hydrolysis reactions in strong, hot nitric acid to break down the dibutyl phosphate (DBP) to monobutyl phosphate (MBP), phosphoric acid $\left(\mathrm{H}_{3} \mathrm{PO}_{4}\right)$ and butanol. This method requires long reaction times $(60$ hours) and results in a dilute product solution $(0.1 \mathrm{~g} \mathrm{Pu} / \mathrm{l}$ in $8 \mathrm{M} \mathrm{HNO}$ ), which can be processed with existing equipment in F-canyon ${ }^{2}$.

Alternatives to the baseline recovery flowsheet have been investigated over the last 9 months and fall into 3 categories:

1) Separate DBP and Pu in carbonate medium prior to acidification

2) Improve the flowsheet by increasing the rate of DBP destruction and/or displacement of $\mathrm{Pu}$ with $\mathrm{Zr}, \mathrm{U}$,or $\mathrm{Th}$.

3) Shorten the flowsheet by elimination of extended boiling and use anion exchange to recover and concentrate the Pu.

Each of these areas will be discussed in detail below; however, the anion exchange route is the only one that is currently advanced enough to be considered useful for plant use. The specific resins and equipment for anion exchange processing in $\mathrm{F}$ canyon have not been evaluated.

\section{DISCUSSION}

The literature has a number of references aimed at the DBP separation problem. $\mathrm{ANL}^{3}$ has even developed a solvent extraction flowsheet to separate DBP and MBP from actinides in carbonate wash solutions. Although that approach is far too elaborate to be considered for the current problem, it is representative of the large body of ideas that have been looked at to find a better way of handling high plutonium-loaded carbonate wash solutions. For this study, ideas that did not appear to be adaptable to existing equipment and operation were not given significant study. This limited this work to a resin column that could be used in a jumper between tanks, to existing unused anion exchange equipment, or to some variation on a dissolver/evaporation process.

Baseline Extended Boil Treatment. The approach taken in our earlier work was to utilize the increased solubility of DBP-Pu in hot, strong nitric acid solutions for addition of Pu-DBPcarbonate solution and allow acid hydrolysis reactions in boiling nitric acid to break down the DBP to MBP, $\mathrm{H}_{3} \mathrm{PO}_{4}$ and butanol. Pu-DBP soluble acid solutions were obtained in a short time (4-8 hrs), but the resulting Pu could not be completely recovered by solvent extraction. Acid hydrolysis was continued ( $40-60 \mathrm{hrs}$ ) until the plutonium retention by the solvent was acceptable $\left(<10^{4} \mathrm{~d} / \mathrm{m} / \mathrm{ml}\right.$ ). Aqueous phase rate constants for the destruction of DBP in $8 \mathrm{M} \mathrm{HNO}$ are in the range of $10-20 \%$ per hour', resulting in a half life of DBP of 4 to 7 hours. This allowed 
WSR - -RP-92-0461

Page 3 of 5

additional carbonate solution to be added after 8 hours, but because the acid concentration was lower (due to dilution and neutralization effects), less carbonate could be added on successive additions. Another limitation is the possible build-up of MBP in solution as the DBP breaks down (Pu-MBP has limited solubility in nitric acid systems ${ }^{6}$ ). The total organic content of the carbonate solution is between 0.3 and $0.5 \%$. These constraints led to the recommendation of a two-addition flowsheet followed with an extended boil of 40-60 hours. The product solution is low in DBP and has a Pu concentration of roughly $0.05 \mathrm{~g} / 1 \mathrm{Pu}$ and $8-9 \mathrm{M} \mathrm{HNO}$, if total reflux is maintained.

Separation of Pu/DBP in Carbonate Media. Two promising approaches have been discussed in the literature for the separation of DBP from Pu in carbonate solutions. In the first, DBP was removed from the solution by absorption onto an organic based resin, (particularly Rohm and Haas nonionic resins XAD-4, XAD-7 or XAD-16). The other route was to absorb anionic $\mathrm{Pu}$-carbonate complexes (particularly $\mathrm{Pu}^{+6}$ ) onto anion exchange resin or even alumina.

The nonionic resin approach holds the advantage of removal of DBP (and TBP) from carbonate solutions so that acidification of the resulting solution would not have the same solubility or organic content limitations. Navratil' tested the XAD type of resins for removal of DBP from both $\mathrm{HNO}_{3}$ and carbonate streams and found the XAD-7 and XAD-4 to have a reasonable capacity. Bibler studied the XAD-4, XAD-7 and Diaion HP-20 resins for removal of TBP from evaporator overheads that are sent to ETF ${ }^{8}$ and found that the HP-20 had greater capacity for TBP due to its large pore size. Experiments were run with simulated DBPcarbonate solutions with XAD-4, XAD-7, XAD-16, MP-500-FK (anion resin) and HP-20. The XAD-7 and HP-20 appeared to have the most capacity for this application, but it was generally much lower than expected. Some of this was attributed to the difficulty in wetting the resin, but the high capacities for DBP reported in the literature were not obtained when absorption was from carbonate solution.

A capacity of $0.027 \mathrm{ml} \mathrm{DBP} / \mathrm{ml} \mathrm{HP}-20$ resin was obtained in a $5 / 16^{\text {" diameter column }}$ run at $1 \mathrm{ml} / \mathrm{min}(3 \mathrm{~g} / \mathrm{l} \mathrm{DBP}$ in $4 \%$ sodium carbonate). When actual tank 13.5 solution was tested, the alpha activity was observed to pass through the column ( $\mathrm{Pu}$ was not retained in the resin with DBP) and breakthrough occurred after only 6.7 bed volumes of solution passed through the column. Capacity of the HP-20 resin was nearly identical for both the simulated and actual runs. Based on this limited data it would appear that it would take 1700 liters of Diaion HP-20 resin to process 17000 liters of 13.5 solution without reusing the resin. Methanol or another solvent could be used to elute DBP from the resin and the resin could then be reused, greatly reducing the resin requirements. Samples of the effluent developed solids containing no plutonium after two weeks (including those samples taken after breakthrough that still had large amounts of DBP). The alpha activity of the aqueous samples remained constant over this time. $\mathrm{X}$-ray diffraction of the solids showed the presence of a long list of elements including $\mathrm{Al}, \mathrm{Si}$, $\mathrm{Fe}, \mathrm{Sn}, \mathrm{Ca}, \mathrm{Pb}$ and others (no $\mathrm{Pu}$ and very little $\mathrm{P}$ ). An nxplanation for the appearance of these solids has not been established.

Patil ${ }^{9}$ has studied the behavior of $\mathrm{Pu}^{+4}$ and $\mathrm{Pu}^{+6}$ in carbonate solutions and has found distribution coefficients of up to 2000 for $\mathrm{Pu}$ on strong base anion resin or alumina. A $1 \mathrm{i}^{10}$ 
investigated the use of strong and moderate ion exchangers for recovery of $\mathrm{Pu}, \mathrm{U}$ and $\mathrm{Np}$ from carbonate solution. Resin loadings varied from 1 to $40 \mathrm{~g} \mathrm{Pu} / \mathrm{l}$ resin. Elution of the column was performed with upward nitric acid flows to remove the $\mathrm{CO}_{2}$ gas that is generated when the $\mathrm{pH}$ drops. Concern about possible plutonium polymer formation on the column during elution was not discussed. This approach is by far the most direct route to recovery of the plutonium from carbonate wash solution that has been discussed in the literature. Experimental work on this approach has not been attempted at SRL. Proper choice of the ionic form of the resin and a better understanding of the behavior of $\mathrm{Pu}-\mathrm{CO}_{3}$ as a function of $\mathrm{pH}$ to avoid conditions that could lead to polymer formation is essential in order to develop confidence in this approach.

Rate Enhancement/Plutonium Displacement. The rate of acid hydrolysis for the destruction of DBP has the potential of being significantly improved by addition of $\mathrm{Zr}, \mathrm{Th}, \mathrm{U}(\mathrm{IV})$ or U(VI) based on the effect o' these metals on TBP decomposition ${ }^{4} . \mathrm{Al}, \mathrm{Zr}$, and $\mathrm{U}$ are also identified as ions that strongly complex DBP in analytical tests. Holcomb ${ }^{\prime \prime}$ attempted to displace the $\mathrm{Pu}$ in $\mathrm{Pu}-\mathrm{DBP}$ solvent wash solution with $\mathrm{U}-238$ and use that as 1 st cycle feed. Although the conditions used produced DBP solids, that approach should work. Some work with $\mathrm{Zr}$ and Al had been planned at SRL, but has not been performed because of the lack of available analytical methods for determination of the relative amounts of TBP, DBP, MBP and phosphoric acid from acid solutions to follow the progress of the hydrolysis reaction.

Anion Exchange Recovery/Concentration. The reason for the extended boil step in the baseline flowsheet was that after 8 hours of boiling to destroy DBP, the solvent Extraction and Strip Pickup Test did not meet the solvent quality criterion of less the $10^{4} \mathrm{~d} / \mathrm{m} / \mathrm{ml}$ alpha activity. Use of anion exchange to recover the plutonium from stable Pu-DBP nitric acid solutions can recover the $\mathrm{Pu}$ and discard the $\mathrm{DBP}$. Anion exchange will produce a product of reasonable $\mathrm{Pu}$ concentration that can be sent to FB-Line without the extended boiling cycle (to reduce the DBP content) or multiple solvent extraction passes (to increase the product concentration to reasonable levels).

Two anion exchange experiments have been performed with plant solvent wash solutions. A single addition of carbonate solution was added and boiled for 4 to 8 hours to destroy enough DBP to make the solution stable. Ferrous sulfamate (FS; was used to reduce any $\mathrm{Pu}^{+6}$ that may have formed during boiling, and the resulting $\mathrm{Pu}^{+3}$ was oxidized to $\mathrm{Pu}^{+4}$ by heating moderately for 30 minutes . A 5/16" diameter $5 \mathrm{ml}$ column of Lewattit MP500-FK was prepared. During loading and washing ( 4 column volumes), $0.5 \%$ of the $\mathrm{Pu}$ remained in the waste stream. Ninety percent of the total phosphate appeared to pass directly through the resin in the effluent and most of the remaining $10 \%$ was in the wash (analysis was by persulfate digestion and spectrophotometric analysis of a phosphomolybdate complex ${ }^{12}$ ). No evidence of DBP-Pu solids was visible in the product solutions one month later.

Some limited testing of the flowsheet using the actual type of resin that would be used and taking into account equipment considerations would be desirable prior to scale-up of this process in $\mathrm{F}$ canyon. 
WSRC-RP-92-0461

Page 5 of 5

\section{Acknowledgement}

D.J. Reif, J.H. Gray and M.C. Thompson have made significant technical contributions to this effort during the course of this investigation. A.E. Scott and K.J. Kalbaugh performed the vast majority of the experiments.

\section{References}

' D.J. Reif, E.A. Kyser, J.H. Gray, "Processing Carbonate Wash Solution(U), WSRC-RP-911028

"Delano, D.M., "Processing 13.5 Carbonate Wash Solution(U), NMP-STF-91-0186

${ }^{3}$ E.P. Horwitz, G.W. Mason, C.A.A. Bloomquist, R.A. Leonard, and G.J. Bernstein,"The Extraction of DBP and MBP from Actinides: Application to the Recovery of Actinides from TBP-Sodium Carbonate Scrub Solutions", Actinide Separations, ACS Symposium Series 117 , 1980, pg 475-496

${ }^{+}$W.W. Schultz, J.D. Navratil, ed, The Science and Technology of Tributyl Phosphate, Volume I, CRC Press, 1984, pg 147, 288

"L.L. Burger, "The Decomposition Reactions of Tributyl Phosphate and Its Diluents", Progress in Nuclear Energy Series III Process Chemistry, F.R. Bruce, J.M. Fletcher, H.H. Hyman, editors, Pergamon Press, 1958, pg 311

' J.M Cleveland, The Chemistry of Plutonium, American Nuclear Society, 1979, pg 442

' J.D. Navratil, "Removal of Solubilized Solvent Extractants from Aqueous Waste Streams", Journal of Nuclear Science and Technology, Vol 18, No 7, July 1981, pg 561-2

${ }^{8}$ J.P. Bibler, "Removal of TBP from Low-Level Radioactive Wastewater at the Savannah River Plant Using Non-Functionalized Resins", pg 307-10

${ }^{9}$ M.M. Charyulu, I.C. Puis, A. Kadam, M.Ray, C.K. Sivaramakrishnan, S.K. Patil, "The Behaviour of Plutonium in Aqueous Basic Media", Journal of Radioanalytical and Nuclear Chemistry, Articles, Vol 152, No 2, 1991, pg 479-86

${ }^{10}$ S.A. Ali, H.J. Ache, "Actinide Separation from MAW Process Streams via lon-Exchange Techniques",Radiochimica Acta, Vol 36, 1984, pg 89-94

"H.P. Holcomb, Personal Comunications, June thur Aug 1991

" M.A.H. Franson, Editor, Standard Methods for the Examination of Water and Wastewater, 16th Edition, American Public Health Association, 1985, pg 437-453

${ }^{13}$ D. J. Reif, Laboratory Notebook, WSRC-NB-90-122, WSRC-NB-90-123

${ }^{14}$ E.A. Kyser, Laboratory Notebook, WSRC-NB-89-5 

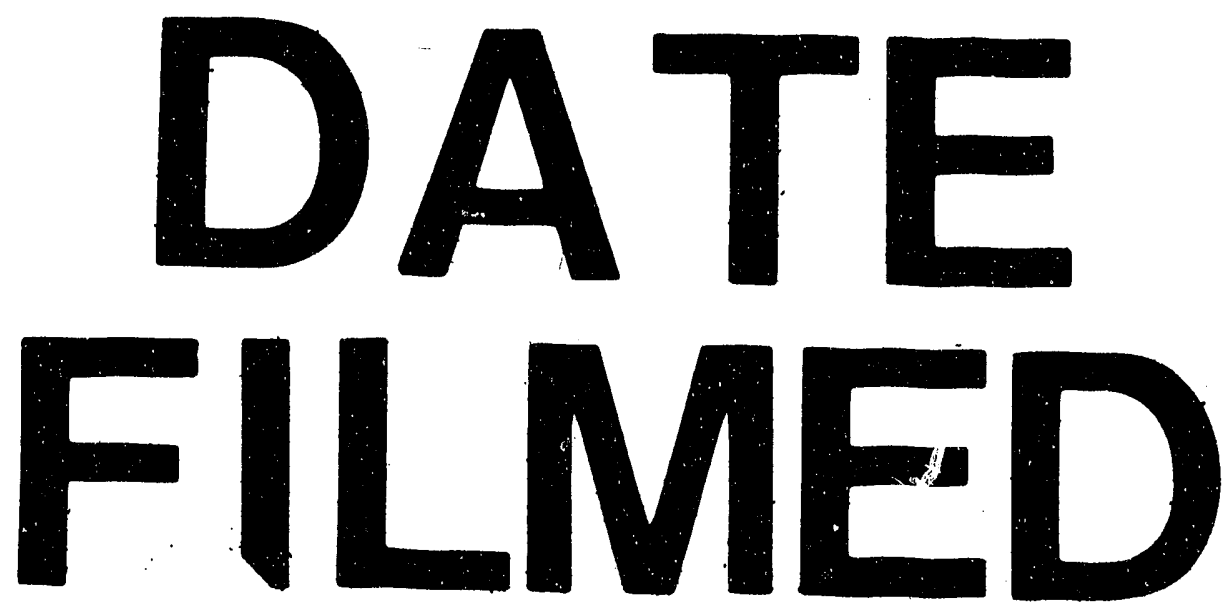

$01 / 20 / 93$ 
